\title{
Attitude towards problem-based learning and its relationship with locus of control and academic self-concept among medical students
}

\author{
Mona Mohamed Ibrahim Abdalla', Mahmoud Said Abdelal ${ }^{2}$ and Siew Choo Soon ${ }^{1}$ \\ ${ }^{1}$ Department of Physiology, Faculty of Medicine, MAHSA University, Jenjarom and ${ }^{2}$ Department of Psychology, \\ International Academy of Achievement, Cyberjaya, Malaysia
}

Purpose: This study aimed to assess the degree of acceptance of problem-based learning (PBL) among phase one medical students and its association with academic self-concept (ASC) and internal locus of control (ILOC).

Methods: A 5-point Likert scale valid and reliable questionnaire assessing the attitude towards PBL, ASC, and ILOC was given to phase one medical students at MAHSA University. Data were analysed using IBM SPSS ver. 22.0 (IBM Corp., Armonk, USA). Results: Out of 255 participants, there were 84 males and 171 females, 175 Malaysians and 80 non-Malaysians. The results showed an overall acceptance of PBL with a mean of $3.7 \pm 0.07$, ASC of $3.5 \pm 0.05$ and ILOC of $2.9 \pm 0.05$. Females showed a higher significant acceptance of PBL, ASC, and ILOC as compared with males. There was no difference between Malaysians and non-Malaysians in any of the variables measured. Simple regression analysis revealed a significant predictive effect of acceptance of PBL on ASC and ILOC ( $r=0.44$ and $r=0.88$, respectively).

Conclusion: The higher the acceptance of PBL among students, the higher is the ASC and ILOC. This reflects the importance of PBL as a teaching method as well as the importance of increasing the level of appreciation of PBL amongst students.

Key Words: Problem-based learning, Internal-external, Academic self-concept, Academic success, Active learning

\section{Introduction}

A strong education is the basic element of development of societies. Academic excellence is the hope and pride of not only each and every student but also the hope of parents, teachers and educational institutions [1]. The excellence in academic performance requires from the students the ability to understand and grasp the subject's contents which involves not only memory work but some non-cognitive factors such as self-concept, self-efficacy and other student's perceptions [2]. In the context of medicine, William Osler realized in 1899 that the complexity of medicine had already progressed beyond the capacity of teachers to teach everything that students would need to know [3]. From that concept emerged the need of developing and using active teaching strategies that aims to build the ability of medical students to identify what they need to know by themselves.

Problem-based learning (PBL) is one of instructional formats that have become commonly used in medical
Received: October 27, 2018 • Revised: December 31, 2018 • Accepted: February 7, 2019 Corresponding Author: Mona Mohamed Ibrahim Abdalla (https://orcid.org/00000-0002-4987-9517) Department of Physiology, Faculty of Medicine, MAHSA University, Bandar Saujana Putra, 42610 Jenjarom, Selangor, Malaysia

Tel: +60.1111362625 Fax:+60.17.3522107 email: monaalbetar@yahoo.com
Korean J Med Educ 2019 Mar; 31(1): 11-18.

https://doi.org/10.3946/kjme.2019.114

eISSN: 2005-7288

(C) The Korean Society of Medical Education. All rights reserved. This is an open-access article distributed under the terms of the Creative Commons Attribution Non-Commercial License (http:// creativecommons.org/licenses/by-nc/3.0/), which permits unrestricted non-commercial use, distribution, and reproduction in any medium, provided the original work is properly cited. 
schools since 1969 when it was first implemented at McMaster University [4]. It is characterized by small group learning experience where the students work on open-ended problems that are similar to real-life clinical cases. In addition to the knowledge that students gain in PBL, some skills such as lifelong learning, critical thinking, and working in a team seemed to be more positive when compared to conventional, lecturebased instruction [5]. Literature provided evidences on the benefits of PBL as an educational strategy as compared to those of traditional methods [6]. The active and engaging learning environment in PBL using clinically-oriented cases empower the students with the ability to identify what they need to learn to solve those problems. The confidence of the students to interact within the group, and their ability to express themselves, are closely related to self-concept which is defined as the way an individual perceives himself and his potential to evaluate his strength and weakness [7]. The student's perception of his/her academic ability is closely related to actual achievement and well-being. This academic self-concept (ASC) is formed through experiences with the learning environment and is heavily dependent on the social comparison of self to others as a frame of reference $[7,8]$. This research hypothesises that one of the benefits of PBL as an instructional method is the development and enhancement of the academic selfconcept among students.

One of the key factors responsible for academic performance is the individual's beliefs about what attributes success or failure and individual's expectations regarding the control over events. Simply, what and who is responsible for his/her success or failure. That is called locus of control (LOC) [9]. There are two sources of control, internal and external. Individuals with internal locus of control (ILOC) believe that they control their own destiny. They also believe that their own experiences are controlled by their own skills or efforts. An example would be "The more I study, the better grades I get" [9]. On the other hand, individuals who tend to have an external LOC tend to attribute their experiences to fate, chance, or luck. Out of 275 testable hypotheses, where academic achievement and LOC were measured, $70 \%$ found internals to have significantly higher academic achievement than externals [9]. This strengthens the significant contribution of the high sense of self control with positive outcomes as compared with negativity associated with the lack of this sense of self control. The development and type of LOC whether internal or external is influenced by stimuli from the surrounding learning environment involving reinforcement, rewards, or punishment that shape student's cognitive and affective outcomes as well as values [10]. The student-centered nature of PBL as a learning tool that rely on the active participation of the students is hypothesized to enhance their self-confidence and subsequently enhances their sense of self control. The way by which PBL is conducted and facilitated affects the degree of student's appreciation to such environment and subsequently affects their active participation in PBL. Based on that hypothesis, this study aimed to assess the degree of acceptance of PBL among phase one medical students and its association with their ASC and LOC. Each of PBL, ASC and LOC has been studied with academic achievement but no studies have been done to show the potential predictive effect of acceptance of PBL on ASC and ILOC.

\section{Methods}

\section{Participants and study design}

This is a cross-sectional study that was conducted 
among phase one medical students at MAHSA University who participated voluntarily in this study. The study design was approved by the Research Management Committee of MAHSA University (IRB approval no., RP8112/15). Written informed consents were obtained. $\mathrm{Me}^{-}$ dical curriculum at MAHSA University is taught over 5 years that is divided into two phases; phase one is carried out in the first 2 years, also known as preclinical years, while phase two involves the last 3 years; also known as clinical phase. PBL is one of the teaching and learning tools used in phase one. Phase one students learn basic medical sciences in the form of systemic blocks, with each block ranging in duration from 5 to 7 weeks inclusive of two PBLs per block. Each PBL is delivered over three sessions, 2 hours each over 3 weeks. During the first session, a clinical case scenario is given to students whereby they discuss among themselves under the supervision of a facilitator and decide about learning issues; what they need to know to solve this problem. During the second session, students will come prepared with the knowledge needed to be presented, shared, and discussed. The third session was used to assess student's learning experience from PBL.

\section{Materials}

A self-administered questionnaire of a 5-point Likert scale was circulated to phase one medical students. The questionnaire was divided into three sections, section $\mathrm{A}$ included a 10-item scale to assess students' attitude towards PBL which was adapted and modified based on previous studies [11-13]. The items of the scale aimed to assess two domains of the previously used PBL perception scale which are the appreciation of PBL as a learning tool and students' motivation and participation within the group. Section B of the questionnaire consisted of an 8-item scale to assess the ASC. The items of the scale were adapted from the ASC scale used by
Liu et al. [14] in 2005 and modified by the researchers. The items used in the ASC scale assess the academic self-confidence, abilities and effort. Section $\mathrm{C}$ consisted of an 8-item scale assessing the ILOC which was developed by the researcher based on Rotter's Locus of Control Scale [15].

\section{Validity and reliability of the scales}

The three scales were circulated to experts (academic experts in medical education and psychology) for revision of their content validity before implementation. A pilot study was conducted on 20 students to test tools feasibility, and applicability followed by appropriate modifications prior to data collection for the actual study. Moreover, the reliability of the tools was estimated using the Cronbach's coefficient $\alpha$ test which showed higher level of internal consistency.

\section{Analysis}

The data were analysed using IBM SPSS ver. 22.0 (IBM Corp., Armonk, USA). Descriptive statistics, independent samples T-test, and simple regression analysis between the students' attitude towards PBL as an independent variable on the ASC and ILOC as dependent variables were done. A p-value was measured to indicate the presence or absence of significant differences. In addition, to quantify the magnitude of the difference, Cohen's d effect size was calculated for the significant differences and the effect was interpreted according to the following Cohen's d effect size indices: $\leq 0.2$ is considered small, 0.5 is considered as medium ( $\geq 4 \leq 6$ ), $\geq 0.8$ is considered large, and 1.3 is considered very large $[16,17]$.

\section{Results}

The reliability of the scales used were confirmed 
statistically with Cronbach's coefficient $\alpha$ of 0.92, 0.72, and 0.87 for PBL, ASC, and ILOC scales, respectively.

\section{Descriptive statistics of the participants based on the year of study, nationality, and gender}

A total of 255 students participated in the study. One hundred and forty-one students representing 55.2\% were from first year, 114 students representing $44.7 \%$ were from the second year, 175 of them were Malaysian (68.6\%) versus 80 non-Malaysian (31.4\%). One hundred and seventy-five were females (67.1\%) versus 84 males (32.9\%).

\section{The attitude towards problem-based learning, academic self-concept and locus of control among phase one medical students}

Out of a Likert score of 5 , the results showed a positive attitude of phase one medical students towards PBL with a mean \pm standard error of mean of $3.7 \pm 0.7$, an ASC of $3.5 \pm 0.5$, and ILOC of $2.95 \pm 0.04$. Students of an ILOC mean that was lower than the mean of the whole sample were considered externally-oriented; external LOC and students who scored a higher mean were considered internally-oriented; ILOC. Our results showed that $51.4 \%$ of the participants have external LOC while $48.6 \%$ have internal LOC.

\section{The difference in the attitude towards problem-based learning, academic self- concept and locus of control based on study year, gender and nationality}

The results showed a significant difference between year one and year two medical students in their ASC but they were not different in their attitude towards PBL neither their ILOC (Table 1). According to Cohen's d size effect, the difference between year one and year two in ASC was of moderate importance (Cohen's d effect size $=0.44$ ). The results also reported an absence of any difference between Malaysian and non-Malaysians in the attitude towards ASC and ILOC. The results showed that appreciation of $\mathrm{PBL}$ among females were higher than males, and also females showed a higher mean of ASC and ILOC (Table 1). The effect size of the significant difference between males and females in their attitude towards PBL was of small importance; Cohen's d effect size of 0.3. While the effect size of the differences between males and females in their ASC and ILOC was of moderate importance; Cohen's d effect size of 0.4 for both.

\section{The predicted effect of attitude towards problem-based learning on the academic self-concept and internal locus of control}

Simple regression analysis between attitudes of the

Table 1. The Means of Attitude towards Problem-Based Learning, Academic Self-Concept and Locus of Control Based on the Year of Study, Gender, and Nationality

\begin{tabular}{|c|c|c|c|c|c|c|c|c|c|}
\hline \multirow[b]{2}{*}{ Variable } & \multicolumn{3}{|c|}{ Study year } & \multicolumn{3}{|c|}{ Gender } & \multicolumn{3}{|c|}{ Nationality } \\
\hline & $\begin{array}{l}\text { Year } 1 \\
(n=141)\end{array}$ & $\begin{array}{l}\text { Year } 2 \\
(n=114)\end{array}$ & $\mathrm{p}$-value & $\begin{array}{l}\text { Males } \\
(n=84)\end{array}$ & $\begin{array}{l}\text { Females } \\
(\mathrm{n}=171)\end{array}$ & $\mathrm{p}$-value & $\begin{array}{c}\text { Malaysian } \\
(\mathrm{n}=175)\end{array}$ & $\begin{array}{l}\text { Non-Malaysian } \\
\quad(n=80)\end{array}$ & p-value \\
\hline Problem-based learning & $3.8 \pm 0.05$ & $3.7 \pm 0.07$ & 0.1 & $3.6 \pm 0.09$ & $3.8 \pm 0.04$ & $0.01^{\text {al }}$ & $3.7 \pm 0.06$ & $3.8 \pm 0.07$ & 0.4 \\
\hline Academic self-concept & $3.6 \pm 0.03$ & $3.4 \pm 0.05$ & $0.02^{\mathrm{al}}$ & $3.4 \pm 0.06$ & $3.6 \pm 0.03$ & $0.02^{a)}$ & $3.5 \pm 0.03$ & $3.54 \pm 0.05$ & 0.9 \\
\hline Internal locus of control & $2.9 \pm 0.05$ & $2.9 \pm 0.08$ & 0.5 & $2.8 \pm 0.08$ & $3.03 \pm 0.05$ & $0.02^{a)}$ & $2.9 \pm 0.05$ & $3.02 \pm 0.08$ & 0.3 \\
\hline
\end{tabular}

Data are presented as mean \pm standard error of mean. A p-value $<0.05$ is considered significant.

a) Significant difference between the corresponding groups. 
Mona Mohamed Ibrahim Abdalla, et al : Problem-based learning, academic self-concept and locus of control

Table 2. Simple Regression Analysis of Attitude towards PBL as an Independent Variable and Academic Self-Concept as a Dependent Variable

\begin{tabular}{|c|c|c|c|c|c|}
\hline \multirow{2}{*}{ Model } & \multicolumn{2}{|c|}{ Unstandardized coefficients } & \multirow{2}{*}{$\begin{array}{c}\text { Standardized coefficients } \\
\text { Beta }\end{array}$} & \multirow{2}{*}{$\mathrm{t}$-value } & \multirow{2}{*}{ Significance } \\
\hline & B & Standard error & & & \\
\hline Constant & 2.332 & 0.154 & & 15.101 & 0.000 \\
\hline PBL & 0.317 & 0.041 & 0.440 & 7.794 & 0.000 \\
\hline
\end{tabular}

A p-value $<0.05$ is considered significant.

PBL: Problem-based learning.

Table 3. Simple Regression Analysis of Attitude towards PBL as an Independent Variable and Internal Locus of Control as a Dependent Variable

\begin{tabular}{|c|c|c|c|c|c|}
\hline \multirow{2}{*}{ Model } & \multicolumn{2}{|c|}{ Unstandardized coefficients } & \multirow{2}{*}{$\begin{array}{c}\text { Standardized coefficients } \\
\text { Beta }\end{array}$} & \multirow{2}{*}{ t-value } & \multirow{2}{*}{ Significance } \\
\hline & B & Standard error & & & \\
\hline Constant & 0.004 & 0.122 & & 0.035 & 0.972 \\
\hline PBL & 0.942 & 0.031 & 0.883 & 29.931 & 0.000 \\
\hline
\end{tabular}

A p-value $<0.05$ is considered significant.

PBL: Problem-based learning.

participants towards PBL as an independent variable (predictor) and ASC showed a significant positive predictive effect of attitude towards PBL and ASC of 0.44. This means that when there is an increase of acceptance of PBL by one unit, this will result in an increase of the ASC by 0.44 (Table 2). Simple regression analysis between attitudes of the participants towards PBL as an independent variable (predictor) and ILOC showed a significant positive predictive effect of attitude towards PBL with ILOC; an increase of acceptance of PBL by one unit will improve the ILOC by 0.88 (Table 3 ).

\section{Discussion}

This study analyzed the attitude of phase one medical students at MAHSA University, Malaysia towards PBL and the potential effect of this attitude on two important non-cognitive factors; ASC and LOC that literature has confirmed their role in academic excellence [1]. We hypothesized that the advantages of PBL are not limited to the development of self-directed learning skills but also involves the development of how the students perceive their academic abilities and their beliefs of self-responsibility about their success or failure. These are crucial for medical profession. The aims of medical curriculum are not limited to gather knowledge but also to develop student's non-cognitive factors crucial for the future needs of the profession. The present study confirmed that MAHSA University medical students appreciated PBL as a learning tool that is in accordance with findings from other studies done in different medical schools $[6,18,19]$. The present study also showed a high sense of ASC and a moderate level of ILOC which could be attributed to their appreciation of PBL as evidenced by the statistically significant positive correlation between students' attitude towards PBL with ASC and LOC reported in the current study. This is in agreement with a study done on medical students in Finland which found a higher ASC among students who are PBL experienced in comparison with other students who are not exposed to PBLs [20]. However, this is contradictory to the findings of another study conducted among first-year medical students in Australia [21] that reported a lower ASC among medical students, a result that was explained by the competitive environment and the use of social comparison in evaluation of student's performance. 
The ILOC reported in the present study can be explained by the high ASC which is in agreement with a study conducted among university students in Italy which reported that the more the students perceive themselves as academically efficient, the more the students undertake the control of everyday circumstances [22]. The gender difference that is found in our study is in accordance with McPherson and Martin [23], McPherson and Martin, 2107 who found that women showed a better ILOC as compared with men. This was also reported in the context of academic LOC which is attributed to the current general dominance of females in higher educational attainment [24]. First-year medical students seemed to have a higher ASC than second-year medical students which can be explained by their higher acceptance of PBL reported in the present study. For this sample of students, Faculty of Medicine at MAHSA University changed from one PBL per block into two PBLs per block and that allowed the first-year students to be exposed to a number of PBLs within 1 year equals to the number of PBLs that second-year students were exposed to throughout the 2 years. This enforces the finding of the present study on the effectiveness of PBL on ASC. The lower level of ASC that second-year students showed as compared with first-year students can be also explained by the decrease in students' professional identity that occurs to medical students as they move during the learning journey [25]. The positive association between the student's appreciation of PBL, their ASC and LOC reflects on the importance of making PBL more enjoyable by the students in a way that motivate them to really actively participate during PBL sessions, which subsequently enhances their beliefs about their academic abilities, improving their self-esteem which subsequently reflects on their LOC. This is in agreement with a study conducted among sport sciences undergraduates [26].

\section{Conclusion}

Attitude of the students towards PBL would explain $19 \%\left(44^{2}\right)$ of student's ASC, and $77 \%\left(88^{2}\right)$ of their ILOC. This reflects the importance of PBL in building and enhancing the cognitive abilities of medical students which greatly depends on student's acceptance and appreciation of PBL as a teaching-learning tool. This direct the attention of the educators to look into the ways by which PBL is delivered and facilitated and emphasis on the environment that control PBL.

\section{The limitations of the study}

Some limitations need to be considered when interpreting the findings of the current study, first is the natural limitation of the educational studies that are questionnaire based which is the subjectivity. Second, it is vital to acknowledge that there are other related factors that affect the ASC and ILOC and more research is needed to fully understand the effect of other variables. Further studies are recommended using a more robust design such as a randomized controlled studies that compare the ASC and LOC among students who are not taught through PBL and those who use PBL.

\section{Recommendation}

This findings requires further research on the LOC, ASC and PBL to be associated with the students' performance.

\section{ORCID:}

Mona Mohamed Ibrahim Abdalla:

https://orcid.org/0000-0002-4987-9517;

Mahmoud Said Abdelal:

https://orcid.org/0000-0003-2467-2269;

Siew Choo Soon: https://orcid.org/0000-0002-7715-0416

Acknowledgements: The authors thank all students who 
have participated in this study, Faculty of Medicine and Research Management Center at MAHSA University for ethical approval and support.

Funding: No funding was received for this research.

Conflicts of interest: No potential conflict of interest relevant to this article was reported.

Author contributions: All authors contributed in the design, data collection, analysis, writing and editing.

\section{References}

1. Akan A. Achievement goals and academic locus of control: structural equation modeling. Eurasian J Educ Res. 2010;(38):1-18.

2. Khine MS, Areepattamannil S. Non-cognitive skills and factors in educational attainment. Rotterdam, Netherlands: Sense Publishers; 2016.

3. Nandi PL, Chan JN, Chan CP, Chan P, Chan LP. Undergraduate medical education: comparison of problembased learning and conventional teaching. Hong Kong Med J. 2000;6(3):301-306.

4. Khoo HE. Implementation of problem-based learning in Asian medical schools and students' perceptions of their experience. Med Educ. 2003;37(5):401-409.

5. Schmidt HG, Rotgans JI, Yew EH. The process of problem-based learning: what works and why. Med Educ. $2011 ; 45(8): 792-806$.

6. Clark CE. Problem-based learning: how do the outcomes compare with traditional teaching? $\mathrm{Br} \mathrm{J}$ Gen Pract. 2006;56(530):722-723.

7. Ma X, Kishor N. Attitude toward self, social factors, and achievement in mathematics: a meta-analytic review. Educ Psychol Rev. 1997;9(2):89-120.

8. Marsh HW. The big-fish-little-pond effect on academic self-concept. J Educ Psychol. 1987;79(3):280-295.

9. Findley MJ, Cooper HM. Locus of control and academic achievement: a literature review. J Pers Soc Psychol. 1983;44(2):419-427.

10. Basak R, Ghosh A. School environment and locus of control in relation to job satisfaction among school teachers: a study from Indian perspective. Procedia Soc Behav Sci. 201 1;29:1199-1208.

11. Habib F, Baig L, Mansuri FA. Opinion of medical students regarding problem based learning. J Pak Med Assoc. 2006;56(10):430-432.

12. Ali WG, El Sebai NA. Effect of problem-based learning on nursing students' approaches to learning and their self directed learning abilities. Int J Acad Res. 2010;2(4): 188-195.

13. Al-Naggar RA, Bobryshev YV. Acceptance of problem based learning among medical students. J Community Med Health Educ. 2012;2(5):1000146.

14. Liu WC, Wang CK, Parkins EJ. A longitudinal study of students' academic self-concept in a streamed setting: the Singapore context. Br J Educ Psychol. 2005;75(Pt 4): 567-586.

15. Rotter JB. Generalized expectancies for internal versus external control of reinforcement. Psychol Monogr. 1966; 80(1): $1-28$.

16. Sullivan GM, Feinn R. Using effect size: or why the $\mathrm{P}$ value is not enough. J Grad Med Educ. 2012;4(3):279282.

17. Scheff SW. Statistic essentials. In: Scheff SW, ed. Fundamental Statistical Principles for the Neurobiologist: A Survival Guide. London, UK: Academic Press; 2016: 37-61.

18. Si J. An analysis of medical students' reflective essays in problem-based learning. Korean J Med Educ. 2018;30(1): 57-64.

19. Yeo S, Chang BH. Students' perceptions and satisfaction level of hybrid problem-based learning for 16 years in Kyungpook National University School of Medicine, Korea. Korean J Med Educ. 2016;28(1):9-16. 
20. Litmanen T, Loyens SM, Sjöblom K, Lonka K. Medical students' perceptions of their learning environment, well-being and academic self-concept. Creat Educ. 2014; 5(21):1856-1868.

21. Jackman K, Wilson IG, Seaton M, Craven RG. Big fish in a big pond: a study of academic self concept in first year medical students. BMC Med Educ. 2011;11:48.

22. Sagone E, De Caroli ME. Locus of control and academic self-efficacy in university students: the effects of Selfconcepts. Procedia Soc Behav Sci. 2014;114:222-228.

23. McPherson A, Martin CR. Are there gender differences in locus of control specific to alcohol dependence? J Clin Nurs. 2017;26(1-2):258-265.
24. Callaghan C, Papageorgiou E. Gender differences in locus of control and student performance in the South African context of accounting studies. Meditari Account Res. 2015;23(3):348-368.

25. Burford B, Rosenthal-Stott HES. First and second year medical students identify and self-stereotype more as doctors than as students: a questionnaire study. BMC Med Educ. 2017;17(1):209.

26. Martin L, West J, Bill K. Incorporating problem-based learning strategies to develop learner autonomy and employability skills in sports science undergraduates. J Hosp Leis Sport Tour Educ. 2008;7(1):18-30. 